\title{
Introduction: one thousand friends
}

\author{
Dean Cocking · Jeroen van den Hoven • \\ Job Timmermans
}

Published online: 24 July 2012

(C) Springer Science+Business Media B.V. 2012

The trouble with you Charles is you want love but you want love on your own terms.

What other terms are there Jeddidihah?

\section{Introduction}

The advent of the online world was first and primarily a revolution in information and access to data. We could gain much more information far more effectively and easier than, say, by going to the library, and access to individuals, groups and organizations became far more broadly available and generally cheaper than by phone, post or travel. In more recent years there has been a second revolution onlinenamely, the rise of social life. Social networking sites have become the predominant use of the internet. Google, for instance, has now fierce competition from Face-book. Facebook is now, together with Amazon, Google and Apple, a formidable force in the market for IT services.

At the forefront of social life becoming the predominant use of the internet has been the pursuit of friendships online. In fact, as is now widely recognized, the average user conducts more than one hundred friendships online. Many users have hundreds of friends online and some have over one thousand. Of course, online social network use of the term 'friend' does not mean online users are necessarily imagining they have many hundred close companion friends, such as friends with

Exchange between Charles Foster Kane and his best friend Jeddidihah Leiland, Citizen Kane, RKO Pictures, 1941.

D. Cocking $(\square)$

Melbourne, Australia

e-mail: Dean.Cocking@police.vic.gov.au

J. van den Hoven · J. Timmermans

Delft, Netherlands

whom one identifies intimately and broadly, rather than, say, narrowly as in friendships merely of pleasure or utility. And plainly, many users are clear enough about the general distinction and navigate the terrain easily - without mistaken or confused views - and so, for instance, have separate accounts divided along the line of their internet and 'real' friends.

However, it is also plain that for many online users the term "friend" does import aspects and demands of 'real' friendship and, so, for instance, when requests to be a friend with another on social networking sites are ignored or denied, its often taken personally-for example, why don't they want to be my friend? ${ }^{1}$ It is also hard to believe that young people-the dominant cohort of social networkers-rarely operate without clarity about the distinction between companion friendship and the appropriation of the term 'friend' by social networking sites. ${ }^{2}$

All of the articles ahead focus on the question of whether there are obstacles presented by online communication environments for achieving ideal companion friendship. In fact, while some apply their claim only to, say, purely textbased worlds, such as email, and some find obstacles across various different online worlds, including social networking sites, Skype and interactive games, all find much the same kind of obstacle for companion friendship onlinenamely, limited and distorted information.

Indeed, all find much the same kind of limitation and distortion of information online to be the main problem.

\footnotetext{
$\overline{1}$ Thanks to Batya Friedman for making this observation in conversation.

2 Moreover, it is hard to believe that traditional world connotations of the term 'friend' are not an important driver for social networking sites' appropriation of the term. In particular, it is hard to believe that the importance (and so selling power) of close, personal relationships to how we understand ourselves and what matters to us is not a driver of social networking sites appropriation of the term. Otherwise, why not simply have 'contact list'?
} 
The main kind of limitations and distortions identified are those due to the primacy online of one's own account and testimony about oneself and the absence of aspects of self that are revealed beyond one's own account. Thus, various aspects of self about which we do not approve, or that we think are not notable or that we simply do not notice are not revealed or are distorted.

Moreover, all essays in this special edition analyze this kind of obstacle in terms of the problem it presents for an Aristotelian view of ideal friendship. The Aristotelian view canvassed across all our discussions characterizes ideal friendship in terms of the self-knowledge that friendship between virtuous people provides and the important necessity of such self-knowledge for the virtuous maintaining and cultivating their virtue. This account of Aristotle's view has been very influential and so is a natural, proper focus for a discussion about whether or not ideal close companion friendships can flourish online. Moreover, the focus on the Aristotelian view has enabled this volume to provide some excellent and detailed description and analyses of various aspects of Aristotle's account.

Interest in the general question of whether there are obstacles to close companion friendships online also presupposes there are people who believe they are pursuing such friendships. The analysis of obstacles to ideal companion friendship online would not only be of nil practical interest otherwise, it would almost certainly be of fairly minimal theoretical interest since the analysis would be of obstacles for pursuing what everyone realized could not be pursued. It is also important then, to consider what kinds of drivers there might be for pursuit of such friendships online.

Obviously, there are all sorts of drivers across different groups, individuals and circumstances. One may simply want to keep in touch with close friends who have moved away. Or one may have become socially isolated, say, because of a disability, and have few opportunities for social life in traditional worlds. But there are other drivers and some may present obstacles of their own and be especially enabled by online communication environments. In the final section of this paper, we highlight the driver of seemingly being able to pursue social life on one's own terms.

First however, analyzing the prospects of undertaking friendship online directs us to think about what the nature and value of friendship is, and so what is at stake if there are obstacles to its pursuit online. Accordingly, we first focus directly on the nature and value of ideal companion friendship. Here we present some more detail of the Aristotelian view that features throughout the discussions ahead. We also sketch an additional suggestion about how to think about ideal friendship. In section 2 "Friendship online" we turn our focus directly to problems facing the pursuit of such friendships online.

\section{Ideal companion friendship}

Aristotle's ethics has been the well-spring for much contemporary discussion of ideal friendship and what might be importantly and distinctively valuable about it. Of the many arguments Aristotle puts in describing ideal friendship the most discussed is his view that it exists between those who are (near) perfect in virtue. This has been widely taken to mean that it is the mutual recognition of one another's virtue that grounds and characterizes the kind of love and respect found in our companion friendships. Thus, it is upon the appreciation of one another's virtue that we have the kind of intimacy, deep affection, trust, loyalty, and so on that is found in such friendships. ${ }^{3}$ Why might this be so?

The most common reason claimed in support of friendship between the virtuous exemplifying the shared activity and reciprocity of ideal friendship is Aristotle's view that such friendship generates self-knowledge that is importantly necessary for virtue. On the ideal of someone we might imagine to be self-sufficient in virtue he says: "If, then, it is pleasant to know oneself, and it is not possible to know this without having someone else for a friend, the self-sufficing man will require friendship in order to know himself." 4 So how does mutual recognition of one another's virtue provide self-knowledge that is necessary for virtue?

The main contemporary answers have been that similarly virtuous friends provide moral role models for one another ${ }^{5}$; enhance one another's moral sensibilities, ${ }^{6}$ and; provide objective views of one another. ${ }^{7}$ Virtuous friends add to one another's self-knowledge by highlighting and so contributing to the development of one another's virtue and by each providing the other with a model of how to act well. As mentioned, all of the papers ahead analyze the prospects of friendship online by considering whether this influential Aristotelian view of ideal companion friendship is able to flourish online. While each discussion is grounded upon, or appeals to, the same kind of Aristotelian view, different approaches to, and aspects of this view, are undertaken and often in significant, analytic detail.

There are also various alternate thoughts worth considering about ideal companion friendship. One we sketch here also comes from Aristotle and may, in addition to the above, further assist future research both on the topic of ideal companion friendship itself and on the question of whether such friendships can flourish online. As noted

\footnotetext{
3 See, e.g., Sherman (1993), Thomas (1989).

4 Aristotle, Magna Moralia, 1213a20-1213b.

5 op cit, Sherman, pp. 105-106.

${ }^{6}$ Op cit, Thomas, p. 147.

${ }^{7}$ Cooper (1980).
} 
above, Aristotle makes many arguments in describing ideal friendship and the fundamental model of valuable relations it presents. One key argument as to why those whom we might imagine to be perfect in virtue nevertheless need friends is not obviously captured by, nor seemingly requires, the contemporary focus on how the self-knowledge provided by virtuous friends might be required for virtue. Rather the focus of this argument is more general, highlighting the reciprocity of our shared activity with others as importantly necessary to what it is to pursue value and have virtue.

For Aristotle, if we imagine someone perfect in virtue and fortune, if this virtue and fortune were unable to be realized through shared activity with others, our imagined ideal is fatally undermined. As he says: "If it's a fine thing, as it is, to do good when one has the goods of fortune, to whom will he do good? And with whom will he live?" ${ }^{8}$ Thus, on this approach, the query about the prospects of companion friendship online is not whether those already (near) perfect in virtue can adjust or 'tweak' one another's virtue, but whether limits and distortions online enable the kinds of shared activity found in companion friendship that are important to generating value and virtue in the first place.

In any case, how more precisely (if at all) might pursuing ideal companion friendship be compromised online?

\section{Friendship online}

As noted, the discussions ahead target distortions and limitations in information about one another's character as the culprit in undermining our pursuit of companion friendship online. This kind of obstacle was identified some time ago in the article Unreal Friends. ${ }^{9}$ In those days the pursuit of 'real' friendship online seemed something of an oddity - a far cry from today, where in one form or another, it is at the forefront of internet use. Unreal Friends argued that 'friendship' pursued solely through text-based communication could not achieve companion friendship since communication solely through the text-based medium is filtered in ways that limit and distort aspects of selfexpression and interaction that ordinarily inform close friendship and provide grounds for the kind of relational identity we construct in it.

The distortion and limitation highlighted was the primacy given to one's own chosen, controlled and voluntary self-presentations in providing the grounds for interaction in purely text-based communication. As noted, what is prone to be missed or distorted are various aspects of

\footnotetext{
8 Aristotle, Magna Moralia, 1213a 26-8; for extended discussion see also, Nicomachean Ethics, Bk. 9, 9, 1169a35-1170b20.

${ }^{9}$ Cocking and Matthews (2000).
}

ourselves about which we do not approve, or we think are not notable or we simply do not notice. Yet ordinarily such things emerge in the communication environments of our traditional social worlds and provide proper grounds for our interaction with, and the development of ourselves in relation to, our companion friends. So, for instance, that our friend is jealous, competitive, bossy or easy-going emerges, say, when going out socially, or at work, may well do so against or without our friend's own more voluntary testimony about things and become grounds for interaction between us and how our attitudes, affections and intimacy are played out in our companion friendship.

The papers ahead both use and move on from this approach in various ways. All apply it to Aristotelian virtue friendship, rather than simply to generic features of companion friendship, such as intimate, deep and broad attachment to one another. Some apply the limitations and distortions only to text-based communication, some to the broader variety of current internet forums for communication and interaction. Some accept the focus of limitations and distortions along the lines of the voluntary/non-voluntary distinction and some revise the focus to be more about information failures in revealing one another's character, whether these failures relate to aspects of one another that are more or less voluntary.

According to evidence cited by some of the articles ahead, the pursuit of friendship online is mostly about maintaining existing friendships. Thus, one might think that even if there are obstacles to pursuing companion friendship online this presents no significant worry about the fate of our social lives. One may naturally presume that our off line social life provides the 'reality' checks against the limiting and distorting effects online worlds might otherwise allow to reign supreme.

No doubt this is often true. However, even if most online pursuit of companion friendship concerns friendships that exist both online and in our traditional social worlds ${ }^{10}$ it may be that the distortions and limitations of online social life are nevertheless sending social life astray in our traditional social worlds. If so, then the general worry is not about replacing our traditional social worlds altogether, but about how our offline social lives are being changed for the worse by the predominance of social life online. ${ }^{11}$

\footnotetext{
${ }^{10}$ Since most users online have well over one hundred friends and it makes no sense to suppose one might have anything like this number of close companion friends, the evidence cannot mean that most friendships online are about maintaining existing offline companion friendships. Rather, while users may have many hundred friends online and only a handful of companion friendships offline most online pursuit of companion friendship is being claimed to regard this handful.

11 The explosion of various kinds of bullying online, especially among our young people, is one plain and central example.
} 


\section{Love on your own terms}

So far our consideration of pursuing ideals of friendship online has focused on limitations and distortions of information one can get about one another's character. However, in addition to identifying such obstacles, or indeed perhaps given such obstacles, what is driving people to pursue friendship online? Obviously, there are a variety of drivers across a variety of cases. We focus here on the driver of being seemingly able to craft one's identity and relationships with others on one's own terms. We think the appeal of this has some broad purchase online and is especially enabled by features of communication and interaction online. Moreover, as our opening quote suggests, this driver is also of long-standing power in our traditional social worlds and plausibly thought to be compounded across our social lives generally on account of its flourishing online (and so of import to maintaining friendships that exist both online and off). So what do we mean by constructing one's identity and relationships on one's own terms?

The tale of Citizen Kane is a tragedy. It is the story of the fall from grace of a great man whose quest to right the wrongs of social injustice, inclusive of others similarly motivated and who were his close friends and colleagues, is corrupted on account of his emerging enormous power and influence. The corruption due to this power is that he comes to regard himself as the sole measure of the good and how to create it, including the good of his personal loves. ${ }^{12}$ Pursuit of the valuable life then, becomes something he pursues solely on his own terms and which blinds him to the point, as he says to his life-long best friend: "what other terms are there?"

A good philosophical representation of this problem is Aristotle's foil of the man self-sufficient in virtue (referenced above). Like Kane, such a man imagines themselves to be the sole arbiter and creator of the valuable life and so a model of the pursuit of value. But such a model is fatally, fundamentally flawed. It is, in particular and for our purposes here, the dynamic relational aspects of companion friendship where one's character is revised and developed beyond what one could have come up with on one's own terms that is crucial to the pursuit of value in ideal companion friendship. This is one important general way of understanding how the limitations and distortions we have seen for online character undermines such ideals.

Such open-ness to others however, is a risky venture and may lead one astray. Some invulnerability to such risks so

\footnotetext{
12 This is perhaps most strikingly captured by his 'creation' of the girl-with whom he thinks he falls in love-into a starlet (in ways increasingly more demanding, ridiculous and foreign to her) after his marriage had fallen into loveless disrepair.
}

that one becomes more 'master of one's domain' is therefore very attractive. No doubt this provides one compelling consideration for thinking of ideal companion friendship in terms of friendship between those already (near) perfect in virtue. Presumably, those already (near) perfect in virtue would, for instance, be less likely to betray our intimate trust and attachment. On the other hand, if we think of those (near) perfect in virtue on a model of selfsufficiency, then we might rightly wonder, with Aristotle, what need they have for the intimacy and attachment of companion friendship.

In her discussion, 'Internet Misogyny and Objectification, ${ }^{13}$ Martha Nussbaum offers an analysis of objectification and of the drivers for it of having atypical power over one's domain in the context of the sexual objectification of women by men that is rampant online. Objectification, on Nussbaum's account, is presented as a cluster concept involving a variety of ideas. These include, treating a person as a tool to one's purposes, lacking in autonomy (as self-determination), lacking agency, being replaceable, lacking subjectivity (and so whose experience and feelings we can ignore), and being reducible to body and appearances.

To explain the objectification and shaming of powerful women Nussbaum develops and applies Nietsche's idea of the resentment of the weak toward the powerful. The weak and resentful among us may spread stories and post images of us that objectify and shame us, and they may do so very easily, across the globe and with anonymity. The key idea is how the weak are able to fight back by creating a different world from the one where they are excluded and where they, and not the powerful, hold sway. In the case of men objectifying and shaming female student peers this "revenge of the nerds" is argued to be even more significant.

The powerful, such as a famous movie star, have a traditional world much greater than the online world that would damn them when constructed by those who are otherwise relatively powerless and are enabled to seek their revenge. An ordinary person, however, does not and so is much less able to 'correct' their shaming and so much more vulnerable to it. The online objectification and shaming of the not-famous can take over and become their worldboth online and off.

For Nussbaum anonymity is the key to their freedom to inflict this hate crime. However, consider how the identity drivers of becoming more individually in control, more self-sufficient and 'master of one's domain' play out in different ways and/or impact more broadly upon the construction of identity and relationships online. At once the design of social networking sites directs users to objectify themselves, others and their relationships online, and does

\footnotetext{
13 The Offensive Internet (2010).
} 
so by appealing to the drivers of increased individual choice, control and self-sufficiency. Interestingly, this objectification of self and others online does not require anonymity.

The most obvious objectification of self by self is the reduction of self to the construction of appearances. Indeed, to those appearances constructed by you seemingly on your own terms. It can be just you that constructs the story and images of who you are-remarkably able to avoid and dismiss influence from others, say, by pushing a button, that disrupt the identity constructed on one's own terms. We can't (typically) do this in our traditional social worlds. The self we construct is met both with resistance and new directions. Reactions such as: "That's ridiculous and for this reason..." or "That's interesting, what about this thought..." So we may be called to revise our view, or we may simply be taken in new directions by the contributions of others.

Of course, so too online-we may also be so "called" and directed online. So what's the point? In the context of the most current use of the online world as a social life, and within this the fact that the main cohort are our young people, the appeal of being enabled to craft identity on one's own terms really gets traction. Early mid-teen years onward are precisely the time of significant moves toward separation from parents and the early days of crafting an identity of one's own more actively and deliberately. Thus, the apparent heightened self-control and self-sufficiency over identity provided online is of special interest and seduction to young people.

Second, objectification of others is ubiquitous on social networking sites with users enabled to treat others instrumentally, deny subjectivity, reduce one another to appearances and regard each other as replaceable. Moreover, just as users are directed to think about themselves as an identity they can construct largely on their own terms, they are also directed to think about these connections to others solely in terms of their choices and control. Typically in our traditional social worlds none of this is true.

As above-mentioned, while many can clearly distinguish between their internet friends and their real friends, it is also plain that many users are not operating with such clarity. This is exactly what you would expect. Young people are only developing their understanding of themselves and their relations with others and the world. How these understandings develop will largely depend upon what they get from their environment-the prevailing attitudes, judgments, norms, conventions and rules of the game. Thus, if, like many teenagers today we increasingly grow up online, then we will be especially vulnerable to taking on or adapting to the conception, in this case of friendship, with which are presented by our social environment.
The world of identities and relationships onlineseemingly crafted largely on one's own terms and enabling atypical control and self-sufficiency-is however, largely an illusion. It is, as one user put it, a 'trick', a very good one, a very seductive one, but nonetheless a trick. ${ }^{14}$ For example, your teenage daughter will tell you, with an innocent straight-face, she has hundreds of friends online. Perhaps she has one thousand. Her social networking site will almost certainly also present an extraordinarily skewed vision of who she is, e.g., endlessly partying, looking very glamorous and pursuing very cool interests.

The broader point is that whatever positions one favorably in a particular milieu-it might be that of the thoughtful academic - and so provides positive self-images within this milieu, tends to dominate self-expression and presentation. Having many friends, or even better, some "celebrity" friends online-as has become the fashionand being directed to think about yourself through overwhelmingly positive images of your own construction, including ones altogether invented, are not the result of one's special abilities to choose one's own identity unhindered by the influence of others and the world around one. The contrary is true. Thus, for instance, many young people have many hundreds of friends online, not because of their desire for power to overcome their weakness, but simply because they will look like a loser if they do not.

It is not hard to understand how this 'big numbers' view of friendship got traction. Your connection of easy access to others is now way beyond the confines of the local school or sporting and interest groups. So too then are the associations you can claim. You will therefore, obviously look like you are not really connected and so fit for this social world if your numbers resemble anything like what is true in our traditional social worlds. Thus, the very seductive driver of apparently heightened self-control, invulnerability and self-sufficiency online is largely an illusion. The controls and choices one makes on one's own terms are largely directed that way by the design and milieu of the online social world.

If we are to think about how we might better design-in protection of key social values online we need to first get clearer about the nature of these values and how, if it all, things are going astray online. The range of analyses canvassed in this special edition offer diverse and fertile grounds for such further research - both on the nature and value of companion friendship and on the prospects of pursuing such friendships online.

Acknowledgments Special thanks to Kylie Cocking for on-going discussion of the ideas in this paper and some excellent editing of an earlier much less readable draft.

\footnotetext{
${ }^{14}$ Guest (2008).
} 


\section{References}

Cocking, D., \& Matthews, S. (2000). Unreal friends. Ethics of Information Technology, 2(4), 223-231.

Cooper, J. M. (1980). Aristotle on friendship. In A. O. Rorty (Ed.), Essays on Aristotle's Ethics (pp. 322-333). Berkeley: University of California Press.

Sherman, N. (1993). Aristotle and the shared life. In N. K. Badhwar (Ed.), Friendship: A philosophical reader. Ithaca, NY: Cornell University Press.
Thomas, L. (1989). Living morally: A psychology of moral character. Philadelphia: Temple University Press.

(2010) The offensive internet. US: Harvard University Press.

Guest, T. (2008). Second lives: A journey through virtual worlds. New York, NY: Random House. 